\title{
MATERIAL TRANSLATION: VALIDATION AND VISUALIZATION AS TRANSDISCIPLINARY METHODS FOR TEXTILE DESIGN AND MATERIALS SCIENCE IN THE CIRCULAR BIOECONOMY
}

\author{
Miriam Ribul (University of the Arts London, UK) \\ Hanna de la Motte (Research Institutes of Sweden, SE)
}

\begin{abstract}
This paper presents a textile design and materials science collaboration during two design residencies in a materials science laboratory for regenerated cellulose research. The first residency evidenced that both disciplines are connected through a materials practice in communication and production of materials. This paper presents the aims of design and scientific research in materials experimentation and the scale of materials in each discipline. The cross-disciplinary collaboration developed transdisciplinary methods for textile design and materials science towards circularity of materials in a bioeconomy. A model for material affinity highlights these two new approaches between the design vision of the textiles designer and scientific method in materials science: validation and visualization.
\end{abstract}

The collaboration led to establishing cellulose-based films as a process that can be made in both the design studio and the science laboratory. This paper presents how textile design prototyping in the materials science laboratory during the second residency was informed by scientific method in a transdisciplinary method of validation. Scientific communication of research is here presented as adopting visualization methods from design. Translation is presented as a term for the design-science material experiments taking place in the science laboratory in the collaboration between the authors.

Improved communication between technical scientists and textile designers is needed to achieve circularity of regenerated cellulose materials in the emerging bioeconomy. This paper addresses translation as a process taking place during textile design residencies in the material science laboratory. The material experiments improved crossdisciplinary communication at the convergence of scientific method, design vision, visualization and validation processes.

\section{KEY WORDS}

Design Science; Regenerated cellulose; Transdisciplinary; Circular bioeconomy; Visualization; Validation process

\section{INTRODUCTION}

This paper presents the design science collaboration between the authors at RISE Research Institutes of Sweden where the design researcher was a participant observer in the materials science laboratory for regenerated cellulose. Design and science are connected through a materials practice, and by collaborations at the raw material stages of the lifecycle, a shared understanding of properties and behaviours may facilitate resourceful material circularity. The paper is an extended version of a conference paper included with permission by the conference editors that discusses one design research residency (Ribul and de la Motte, 2016) and presents new research from a second design research residency. The brief for the two design residencies was to explore how design and science can inform each other when working with regeneration of cellulose for a circular bioeconomy. To explore these questions, the design researcher was embedded in the laboratory work at RISE, documenting the scientific processes and introducing design tools into the scientific environment. The collaboration has lead to identifying that the exploration of a comparable material process in design and science can develop connected approaches in both disciplines. This was explored through making regenerated cellulose films in the science laboratory and bio-plastic films in a design studio lab. This paper proposes how material processes for design and science can evolve to establish a transdisciplinary practice for a circular bioeconomy. The bioeconomy is based on local and renewable bio-materials, such as cotton and wood, and scientific research that was successful in developing regenerated cellulose also from cellulose-based waste textiles. 
A definition of the "Material Affinity" will outline how both disciplines explore materials with their hands. Key approaches to materials experimentation in both disciplines emerged from the lab work and studio practice. The outline of these approaches for each discipline will link to processes and tools for material experiments. The use of different language will demonstrate how this can create barriers and innovation in this context. A "Material Affinity diagram" fields two new areas for design and science in a materials context. These two new areas are evidenced in the research conducted by the authors since the first residency, and are highlighted through the case study of the second research residency at RISE Research Institutes of Sweden. The authors introduce "translation" as a definition of practice blending disciplinary language into transdisciplinary methods that can facilitate a systemic approach to materials in a bioeconomy. Methods explored by the designer during the second research residency for validation of experiments and methods in the scientific research for science communication lead to new insights for the design and science practice.

\section{CONTEXT}

\section{Design and Material Science}

The connection of design and technical science in a circular bioeconomy is that both develop their work through working with materials with their hands. According to Sawyer, both are connected through experimentation and creativity, and a will to create beautiful outcomes (2006). While scientists explore materials from the molecular level, designers work with the material properties that are perceived through the senses (Karana et al., 2014). The Encyclopaedia Britannica (Chisholm, 1911) definition of a chemical affinity is 'the property or relation in virtue of which dissimilar substances are capable of entering into chemical combination with each other.' As analogy, a material affinity defines how tools and methods of different disciplines can merge in a circular bioeconomy as they are connected through a materials practice. This was explored during a residency at RISE Research Institute of Sweden, where the design researcher collaborated with the technical scientist to explore the scientific processes involved in the regeneration of cellulose. This paper maps how both disciplines work with materials, and proposes a model for a material affinity of the disciplines for a circular bioeconomy.

In a take-make-dispose linear system for textiles, recycling is disconnected from the material selection in the design stage. In Vezzoli's Life Cycle Design approach (2014), design considers the impacts of material selection for a product at the beginning of the lifecycle. In the Ellen MacArthur Foundation definition of a circular economy, materials at the end of their life are reinvested in a new loop (2014). This provides the need for materials science and textile design to collaborate. There are other relevant stages for design-science to interact in a material lifecycle such as retail, distribution and use which connect to services, business models and consumer behaviour, however material science and design are linked through what is described by the Science Community Representing Education (SCOR) as practical work with materials (2008). The technical scientist who develops methods for closed loop material recycling and the designer who selects a material at the beginning of the lifecycle are both connected through working with the same material, however with different aims.

This can be related to a question of scale, as described by Oxman (2016),

"The way we view our environment, and interact within it, is ultimately dependent on the lens through which we choose to see it. Choosing is no innocent act. A material scientist will generally explore the physical composition of matter through the lens of properties. A biologist, however, looks at the world not through the lens of properties, but rather through the lens of function. Both live in the same reality, but experience it altogether differently, and therefore act upon it in a singular way. If they could see both views simultaneously, they would link properties and behaviors."

Ito (2016) argues for "antidisciplinary" approaches that "move beyond 'many sciences'-a complex mosaic of so many different disciplines that often we don't recognize when we are looking at the same problem because our language is so different and our microscopes are set so differently."

According to Ito (2016) and Oxman (2016), design and science are located opposite each other in a coordinate plane. In these, design and science connect through art or engineering. Brown et al (nd) explain how the exploration of a design science practice goes back to Buckminster Fuller's work in 1927 and Cross (2001) argues how efforts to bring design closer to the scientific method were unsuccessful.

Karana et al have listed a range of projects that support collaboration between these disciplines; however, designers are still evaluating how to move in the scientific domain (2015). Collaboration is a key word of our time to approach complexity where systemic change is what Rittel and Webber defined a wicked problem (1973). Increased funding pressure, large scale projects and competitiveness require efficient communication between disciplines for an immediate impact on environmental concerns. As both design and materials science work with materials, we need to develop a connected practice for both disciplines in what Drazin calls "material transformations" (2015) at each stage along the material lifecycle. 


\section{Material Approaches}

\section{Film-making}

The residency at RISE Research Institutes of Sweden was split into two parts: one for observation and one for action within the materials science laboratory. However, the design role in this context varied from observation to action, and no linear separation of stages can be made. According to Reason and Bradbury, the methodology of cooperative inquiry in participatory design outlines that inquiries can be linear, Apollonian, or Dionysian, taking a 'more imaginal, expressive, spiralling, diffuse, impromptu and tacit approach to the interplay between making sense and action' (2006). Due to the context of the research where the outcomes were not defined and the approach was open (Muratovski, 2016), a Dionysian approach was chosen. According to Ito (2016), a participatory observer is part of a wider complex system and cannot describe the process in a linear way. The residency provided many potential outcomes for design and science collaboration. However, two main categories crystalised: the first is communication of materials, comprising language and presentation, the second is production or making of materials.

For the development of a practice that considers both textile design and materials science, regenerated cellulosic film materials were chosen for the analysis of processes in each discipline for the following reasons: both require similar processes for making in the materials science lab and design lab, as opposed to regeneration by dissolution and spinning processes that can not be replicated in a design studio due to technical requirements; the science collaborator noted how regenerated cellulose films and bio-plastic films have similar properties and can be achieved in both the design and materials science lab; the film material does not need a context for a specific product at this stage, and invites an experimental approach in both disciplines. Scientific research in cellulose films has been completed (Sundberg et al. 2013, Hameed 2010) and film making is also explored as a material process in design projects (Ribul 2013, Lee nd, Nijkamp 2012). An initial exploration of cellulose films in the science lab supported a "quick prototyping" approach where the scientist and colleagues were involved in exploring a new 'recipe' while the designer introduced design techniques into the laboratory.

The work in the science laboratory evidenced how design and science follow similar approaches of communication and production when working with materials, however at a different scale of materials and with different aims. This connects to Ingold's two fields of anthropological enquiry of visual and material culture (2013): The former is apprehended through the senses, while the latter through making with materials. Table 1 and 2 compare general approaches of design and materials science in the practical exploration of cellulose films. The simplified structure is not to be considered in a linear way, as communication and production happen at several stages throughout the cellulose film making process. An equivalent to the scientific method for design does not exist, however the widely accepted design methodology of the double diamond developed by the Design Council can act as a useful framework for the design process (2005).

Table 1: Communication approaches of design and science with cellulose films

\begin{tabular}{|l|l|l|}
\hline & \multicolumn{1}{|c|}{ Communication } \\
\hline Documentation & $\begin{array}{l}|c| \\
\text { Lab book, excel, pictures, film clips, graphs } \\
\text { and spectra, computing softwares }\end{array}$ & $\begin{array}{l}\text { Sketch book, drawing, photography, } \\
\text { visualizations, film, material samples, } \\
\text { prototypes, descriptions, computing softwares }\end{array}$ \\
\hline $\begin{array}{l}\text { Communication and } \\
\text { presentation }\end{array}$ & $\begin{array}{l}\text { Conference presentations, scientific } \\
\text { publications including data and method } \\
\text { sharing for replication (retesting by others), } \\
\text { internal and external reports }\end{array}$ & $\begin{array}{l}\text { Visual format for presentations, press, web } \\
\text { platforms, social media, exhibitions, films, } \\
\text { animation, events and publications }\end{array}$ \\
\hline
\end{tabular}

Table 2: Production approaches of design and science with cellulose films

\begin{tabular}{|l|l|l|}
\hline & \multicolumn{2}{|c|}{ Production } \\
\hline & \multicolumn{1}{|c|}{ Science } & \multicolumn{1}{c|}{ Design } \\
\hline Preparations & $\begin{array}{l}\text { From observations, questions and problems to } \\
\text { hypotheses, predictions and experimental } \\
\text { plans }\end{array}$ & $\begin{array}{l}\text { Primary and secondary research, identification } \\
\text { of a problem, formulating a research question, } \\
\text { vision or proposal }\end{array}$ \\
\hline Techniques & $\begin{array}{l}\text { Practical laboratory methods/settings and } \\
\text { scientific instruments, computing and } \\
\text { calculating methods }\end{array}$ & $\begin{array}{l}\text { Practical design work through planning and } \\
\text { making with design tools, textiles-specific } \\
\text { techniques or development of new ones }\end{array}$ \\
\hline Experimentation & $\begin{array}{l}\text { Collection of data using the techniques, } \\
\text { replication (iterations and recursions) }\end{array}$ & $\begin{array}{l}\text { Sampling and prototyping using the } \\
\text { techniques, iterations }\end{array}$ \\
\hline Outcome & $\begin{array}{l}\text { Correlations and regressions, conclusions } \\
\text { (theories), products (such as different }\end{array}$ & $\begin{array}{l}\text { Process for design, visual outcome and } \\
\text { product for use }\end{array}$ \\
\hline
\end{tabular}




\begin{tabular}{|l|l|l|}
\hline & materials) & \\
\hline $\begin{array}{l}\text { Analysis and } \\
\text { characterization }\end{array}$ & $\begin{array}{l}\text { Data and product analysis, statistical analysis, } \\
\text { external reviews }\end{array}$ & $\begin{array}{l}\text { Analysis of experience of information and } \\
\text { product by users }\end{array}$ \\
\hline
\end{tabular}

The tables demonstrate how both disciplines follow parallel approaches in the development of practical work with materials in communication and production. According to Sawyer, the scientist aims to create outcomes that are clear, well communicated and presented (2002) and the collaboration evidenced how tools and language differ to design. Peralta and Moultrie have analysed how science explores a hypothesis of reality in the properties of materials, while design follows a vision for what could be (2010). To achieve results, both require what the Wikipedia definition of the scientific method outlines as intelligence, imagination and creativity (nd).

Cellulose films can be produced with shortened cellulosic fibers that are obtained from used cellulosic fibers, therefore link to the circular bioeconomy through providing a system for recycling at a later stage in the material lifecycle. Current research by Ma et al. (2015) and Östlund et al. (2015) into creating high value textiles by regeneration of cellulose fibers are reliant on a production model based on fibers, yarns, textiles and products, and a process where science has to go through engineered yarn technologies to design. This corresponds to Oxman's argument (2016) that science goes to design through engineering. To explore practice-based research that connects design and science without going through engineering, films provided a material process that connects both disciplines. Cross states that design knowledge is acquired through reflective practice, however in order for disciplines to collaborate it is beneficial to find a way to communicate this practice to the scientific method (2001). When working with cellulose films, what we explore is transdisciplinary, or as per Antonelli's definition 'knotty' (2015) as we require knowledge from different disciplines. This implies the complexity of a designer working in a lab and of a scientist exploring design tools.

The residency lead to a low tech approach to making bio-plastic films in an improvised design lab (Ribul, 2013) that is comparable to processes for making cellulose films in the science laboratory. This ensured making was concerned with a similar material scale and similar properties of the material.

\section{The inversion of design and science roles}

The collaboration between design and science in the science laboratory lead to an inversion of roles. The designer observed processes of regeneration of cellulose in the science laboratory, finally producing a dissolution and regeneration of cellulose. The designer introduced design tools into the scientific context of the laboratory: Sketchbooks, work sheets, prototypes and exhibition of samples. The scientist took lead when using the design tools provided for the collaboration. In a cooperative inquiry, where both the designer's and the scientist's questions were explored, the designer does not have the role of the facilitator.

A sketchbook was used to document the collaboration and communicate concepts between the designer and scientist. Both used this to write or draw during conversations. Differences in language can define scientific processes that can also be found in design, however the same words can have a different meaning in each discipline, leading to barriers in communication or innovation: For example, the discussion of an exploration of 'films' was introduced by the designer as a tool for communication, while the scientist described it as a material to explore production models. This lead to the collaborative exploration of regenerated cellulose films. For future design-science collaboration, selecting between communication or production can lead to a better understanding of the shared aims for the collaboration.

Both disciplines encounter barriers to introducing new roles into a daily practice. The introduction of a sketchbook as used to visualise and present possibilities is an exception provided through the collaboration. A designer's conventional practice is not linked to a science laboratory. Incremental changes to the practice were possible through the collaboration in the adaptation of tools from the other discipline: the scientist increased the use of images in scientific presentation slides, not to communicate results, however to engage a wider audience with a 3D representation of materials (Figure 1); the designer considered the scientific method in the production of material samples in the studio practice (Figure 2). This lead to expanded areas for communication and production for both design and science. 


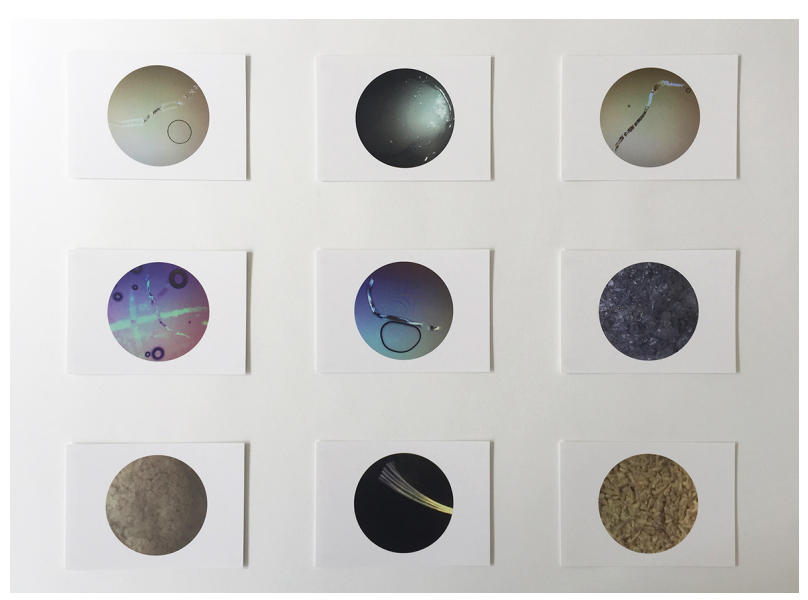

Figure 1: Visualization postcards of raw material stages of regenerated cellulose

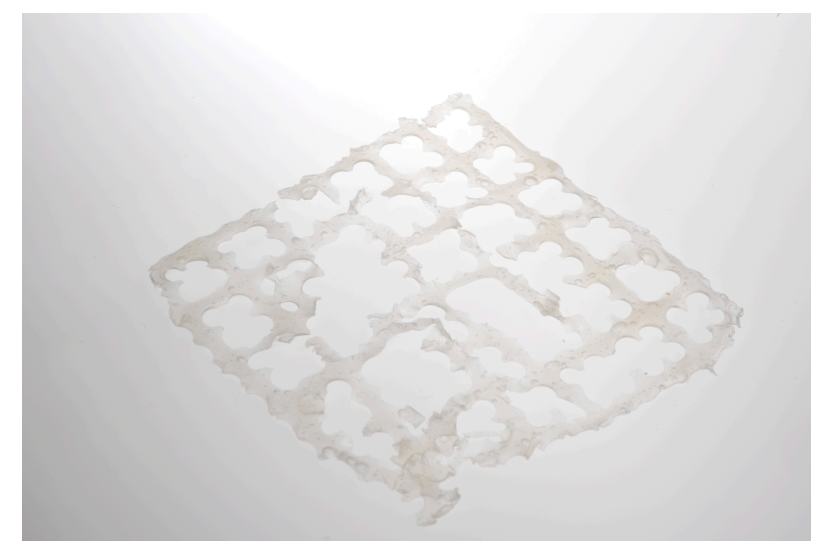

Figure 2: Cellulose-based bio-plastic film experiments in design studio

\section{NEW APPROACHES FOR DESIGN AND SCIENCE}

The first residency evolved over a short period of time, and demonstrated initial results for how a collaboration of design and science can impact practical work with materials towards a "material affinity" between the disciplines. While design and science is often connected to the development of methodologies (Cross 2001, Brown et al. nd), according to Karana et al there is no model for how these can inform each other through collaboration (2015). The practice described as "antidisciplinary" (Ito 2014) or "transdisciplinarity" (Lawrence and Deprés 2004), is one where individuals move fluently between disciplines such as textile design and materials science.

Figure 3 outlines how the first residency resulted in design and science informing each other's practice to lead to new approaches when working with regenerated cellulose films. While design follows a vision through its practice with the perceived qualities of materials at the macro scale of products in the first quadrant, science develops the scientific method through repeatable and tested processes starting at the material's micro scale in the third quadrant. For a closer connection of design and science in a circular economy, both designers and scientists have developed a transdisciplinary practice at a different scale of materials.

The design researcher has evolved an increased understanding of the scientific processes with regenerated cellulose, particularly through the scientific framework of materials and methods to create valid experiments that are repeatable and shareable. The understanding of the material at the micro scale provides a new input for design in a circular economy context: Design considers the scientific method through the development of valid material experiments in the fourth quadrant that are repeatable and tested to create material samples that can be up scaled and shared for a circular economy (Figure 3).

The scientist increased the understanding of the design processes for visualization and communication of the material in a 3D format. Adopting a visual format in science will benefit a collaborative process, as it will provide designers with an increased understanding of the processes involved for recycling and end of life in a circular economy. Through images in presentations or through collaborations with designers to produce compelling prototypes, the new third quadrant for visual scientific communication can engage a wider audience (Figure 3). 


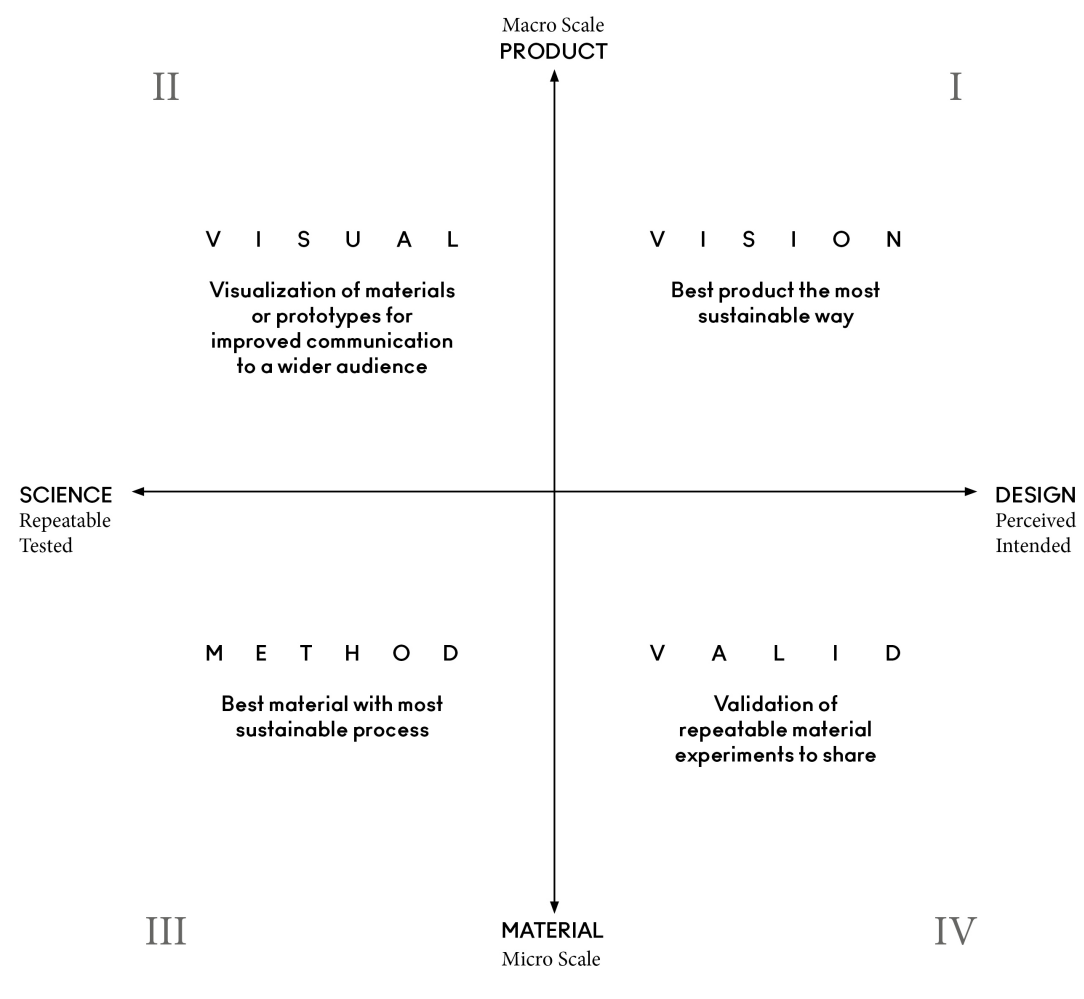

Figure 3: Design - Science Material Affinity diagram.

The first residency also highlighted a need for better communication informed by language. Both researchers have been working in cross-discipline collaborations before, and this supported the collaboration. Textile design and materials science differ in their development of methodology, and questions of explaining the design process for this context have emerged. Like in science, different materials and contexts require different approaches in design. How design and science can work together with materials was further explored in a second residency at RISE Research Institutes of Sweden, beginning from the affinities of practice that are needed for systemic change towards a circular bioeconomy.

\section{TRANSDISCIPLINARY METHODS FOR DESIGN AND SCIENCE}

The two transdisciplinary areas of validation and visualization were then put into practice in the second residency. Visualization would expand the communication of scientific research into methods used by designers; validation would introduce scientific production approaches in design prototyping. This provides a valuable skill set for the authors both engaging with materials towards systemic change in the circular bioeconomy: the designer expands the knowledge of materials to the chemical processes taking place in the science laboratory, and the scientist communicates the research beyond the materials science laboratory to non-scientists.

\section{Validation of design experiments}

The material affinity diagram informed the development of the brief for the second research residency. The aim of the residency was to develop scientifically valid design-science prototypes with regenerated cellulose. The outcomes of the first residency and studio practice highlighted the material properties of the regenerated cellulose films in design prototyping (Figures 4 and 5). These properties informed the development of design experiments for the second residency to create films that can be perceived as textiles. Textiles are described by Igoe as having haptic and visual properties including aesthetics and function (2010). 


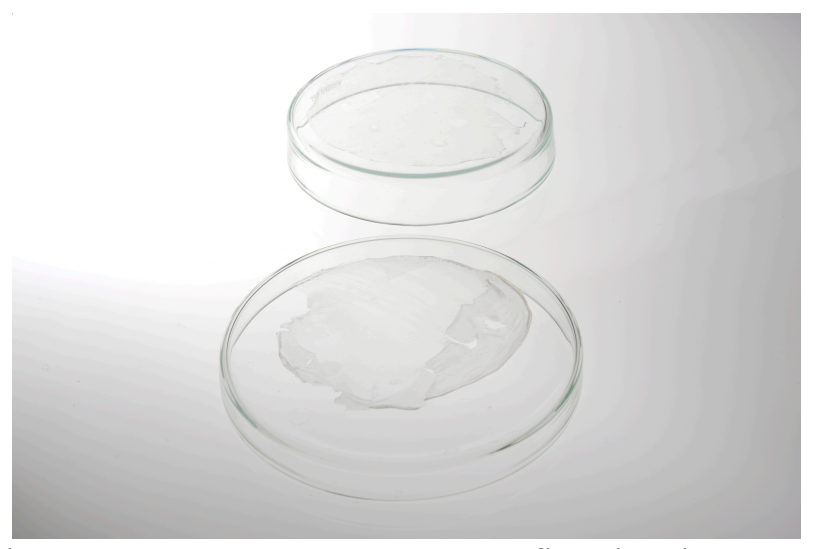

Figure 4: Flat, round regenerated cellulose films in science laboratory

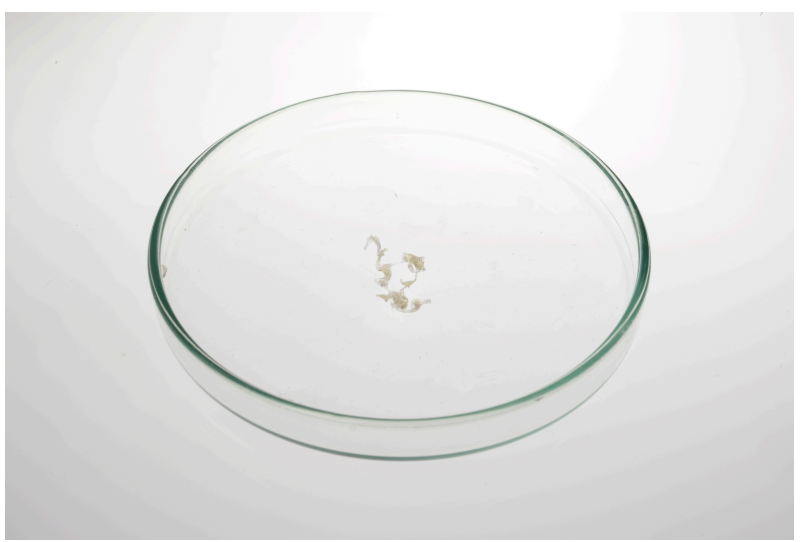

Figure 5: Regenerated cellulose films formed to resemble lace

Through the collaboration between the authors, the set up of the design experiments in the second residency followed scientific methods for cellulose dissolution and regeneration suggested by the technical scientist and based on scientific papers on cellulose-based films. The experiments were recorded in a lab book by the design researcher and followed a new, scientific format of process documentation in design experiments.

Both authors have previously conducted experiments with regenerated cellulose films in a "quick prototyping" approach in the first residency and in a previous design-science collaboration. The validation process of the experiments in the second residency required a methodical approach to design prototyping in the development of the films. The authors considered different experimental plans for the laboratory work.

Validation is a scientific term for experiments that can be replicated by others and are developed through recursions and iterations. "Validation methods involve ensuring that claims to knowledge are tested and approved by the most rigorous standards" (McNiff and Whitehead, 2010). The second residency introduced comparison as a method to prove validation of material experiments. Iterations of material experiments were conducted by introducing variables for comparison. These variables considered the vision of the designer as well as the scientific method required for cellulose dissolution and regeneration. These are described here for each residency.

In the first residency, the authors tested three types of cellulose solvents to find the most suitable one for film production. In the second residency, the validation of the design prototypes was considered through the use of three types of cellulose sources for the dissolution in the best solvent chosen from the first residency to compare the resulting films. For further comparison, different percentages of cellulose were dissolved in the solvent and different types of coagulation baths to regenerate the cellulose from a liquid into a solid film were also compared (Figure 6). 


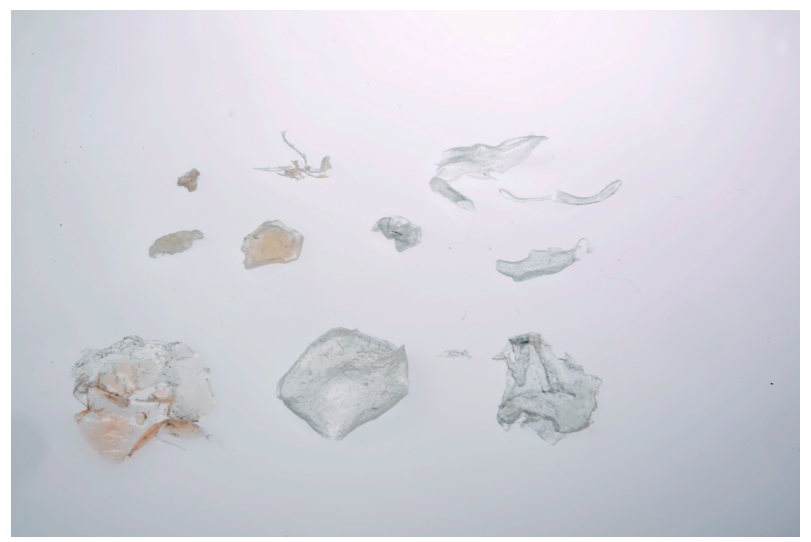

Figure 6: Comparison of regenerated cellulose films in the validation process

The comparison between materials and methods informed the development of the valid process for regenerated cellulose films production for the design experiments. Design tools and processes were used to make flexible films that were closest to the design vision for the prototyping stage. For example, a series of molds was used to form the films (Figure 7). The comparison demonstrated the best shape and surface for the liquid to be regenerated onto in order to consider the design of the molds. In the experiments, molding was used to consider a design process as well as the possibilities of forming cellulose materials in the dissolution and regeneration stages.

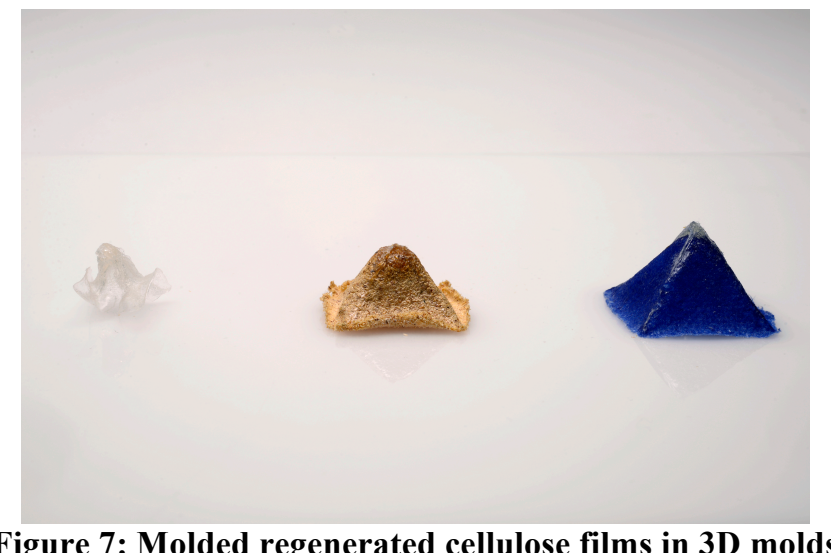

The integration of the scientific method into the design practice evolved through the prototyping. Results from experiments that broke, shrank or hardened required incremental considerations of the most suitable scientific method for design prototyping. An iterative process took place during prototyping that evolved each experiment in response to the possibilities and limitations of regenerated cellulose films. Through a "hands-on" practice with materials, a transdisciplinary method of validation evolved where chemistry and textile considerations were developed at the same time.

Through the documentation of the experiments in a lab book, the design practice transformed from a vision to a consideration of a valid format that could be repeated in a circular bioeconomy. The lab book in the design practice transformed into a lab-sketchbook where both scientific numerical documentation as well as design methods of sketching, visioning and drawing were considered.

As a transdiciplinary method for textile design research in the materials science laboratory, "validation" corresponds to a method of systemic exploration and documentation in the production of material samples that blends design and science approaches. In the material affinity diagram, design prototyping begins at the microscopic scale of materials in chemical recycling. Visioning is the main driver behind the design experiments, therefore textiles knowledge and expertise is still required in the collaboration. However, through validation the experiments are repeatable and can be communicated to scientific research.

It is noted by the design researcher that validation continued to take part in the subsequent practice work with materials, and that the second residency and the collaboration between the authors informed the ongoing methods of the design practice. 


\section{Visualization of scientific research}

The material affinity diagram outcome of the first residency, together with the inversion of roles and the material prototyping by the designer in the secondary residency, informed the technical scientist on the potential of design processes to visualise scientific communication and engage a wider audience in the circular bioeconomy. The scientist increased the understanding of the design process when adapting design tools into the scientific method, in particular in the communication (Table 1) comprising design approaches for documentation, communication and presentation. However, in order to be able to visualise and communicate results, the design process was also reflected upon in the production steps experimentation and outcome, where the design approaches of prototyping and visualization were considered respectively.

Visualization is a term derived from graphic design and computational science and is increasingly used in all design disciplines. The term describes a "representational force of the visualization as a 'picture' of 'data"," (Drucker, 2011). This data can be a vision of the designer or invisible chemical information, and can be represented for example with video, graphics, materials, or images.

In the first residency, a sketch book and drawings facilitated the interdisciplinary communication of the authors, resulting in a shared view of the cellulose film making and how design and materials science could interact in practice (Figures 8 and 9). The consensus was a result of a successful discussion enabled by the introduction of the designer's tools into the context of the technical science. Furthermore, a conversion of microscope images into high quality photographs and picture postcards by the designer enabled a broader view on the possibilities and, expressly, intelligibility of 3D visualization for the technical scientist (Figure 3).

In the second residency, after the development of the valid scientific method for regenerated cellulose films, design tools and processes were used by the designer only to make flexible films close to the design vision for the prototyping stage. The conscious absence of the technical scientist was with the intent to not interrupt the work of the designer with technical considerations or micro scale limitations, but to let the designer's tools and vision act as inspiration for new materials routes and possibilities on a macro scale. The prototypes of the second residency indeed visualized prospective products for the cellulosic materials for the technical scientist, not obvious to be found without the inversion and design lead. As the prototypes could be further explored, also in a subsequent method optimization and validation according to the scientific method, the inversion pictured how an interdisciplinary blend of the scientific method and the design process could result in exciting materials and progress for a circular bioeconomy.

As a transdisciplinary method for materials science, "visualization" here corresponds to the presentation of materials science results for improved communication to a wider audience in the circular bioeconomy. The scientific methodology is the main driver behind technical experiments, and the technical scientific knowledge and expertise is still required and important in interdisciplinary collaborations. However, through visualization of the experiments and outcomes using communicative design approaches described in Table 1, it was in this collaboration exemplified that the understanding between materials science and textile design research could be improved.

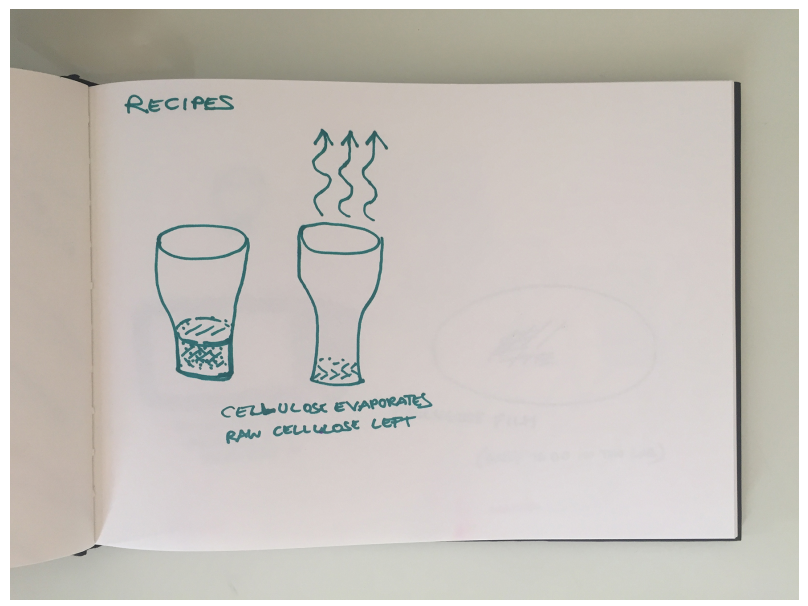

Figure 8: Design sketch for communication of cellulose processes through film 


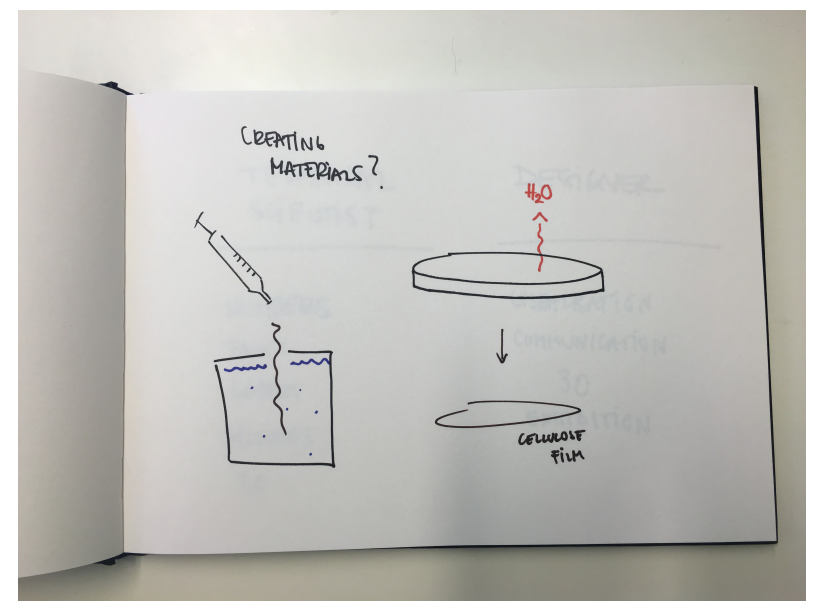

Figure 9: Scientific sketch for production of cellulose films

\section{TRANSLATION}

The collaboration between the authors during the second residency can be described as "translation" between design and scientific processes for the circular bioeconomy. Through the collaboration both authors gained insights into the practical work with materials of the other discipline. This enabled a deeper level of understanding of the material processes in each other's discipline which could not have been achieved through observation of the processes in the materials science laboratory or design studio alone. The design practice took place within the scientific environment and followed the scientific processes for regenerated cellulose. As both authors were present in the laboratory during the experimentations, the residency enabled observation and participation in shared practical work with materials.

The design practice progressed experimentally, testing several iterations with the films to achieve results that can be compared to textiles. Through engaging with the material in design processes that are familiar to the textile designer, an understanding of properties and behavior of regenerated cellulose was gained. The regenerated cellulose films resulting from the practice visualized invisible material properties of cellulose at the molecular scale into a tangible format at the same scale of textile samples. The practice during the residency was informed by "tacit skills" of the textile design researcher. Polanyi was the first to argue that many actions based on "tacit knowledge" give "value to the process of recognising, and making a commitment to, ideas or hypotheses, which may result from a rich understanding and knowledge, but cannot be explained by explicit reasoning (...) gained over life time experience, a theory that is increasingly applied to design and artefacts" (Rust, 2004).

The exploration of the material in the design practice during the residency was open-ended and not specified for a product or application. With a material-driven method, the properties and behaviour of the material informed each stage of material experimentation. This resulted in a wide range of possibilities instead of the development of one process with the material. Material-driven design is defined by van Bezooyen as a process where the material informs the goalposting, to find opportunities (2014). The material-driven method differs to a material-by-design approach. Küchler (2015) describes how, "with materials-by-design, the application requirements often come first, and the material is then connected to meet those needs." In materials-by-design, designers specify the application of the material which is then developed by the scientist. In this residency, the experimental work by the designer was informed by the material properties, not the application. For the scientist, this observation of the design process demonstrated how prototyping made by the designer is enabling new visions of possible products.

The design researcher conducted the experiments independently in the lab and check-in points with the scientist to review the samples from the design practice were invaluable for the understanding of the scientific research. If experiments failed, the technical scientist in the collaboration explained the chemistry, which provided real insights into the processes taking place at the molecular scale. Communication between the authors was based on the material samples resulting from the experiments, and the practice work provided a tool for cross-disciplinary communication through materials and artefacts as described by Wilkes et. al. (2015). Specifically, for the designer working towards a vision of possibilities with regenerated cellulose, the experiments provided an opportunity to test textile processes with regenerated cellulose films and to explore if these can be translated into the scientific experiments. The resulting films provided a form of three-dimensional sketchbook of tangible material experiments for textiles that also demonstrate the limitations of the material through the validation process with the scientific method in design prototyping. The design researcher visualized visions of process through the experiments, which demonstrated the possibilities of cellulose films before further design considerations were made. For example, deep molds for forming the films would limit regeneration and break the sample, which informed the textile process of molding the regenerated cellulose film. 
Design prototyping inside the science laboratory enabled communication between the authors. The residency considered all areas from the material affinity diagram in a process of translation: scientific method and design vision were considered for the material experiments; design prototyping proceeded with a process of validation; and the material samples visualised the opportunities and limitations of prototyping with regenerated cellulose films in a 3D format. The term "translation" is here applied to a cross-disciplinary practice where discipline-specific and transdisciplinary approaches converge. In the material affinity diagram, "translation" would sit in the middle of the two axes. This translation was achieved through a shared practical work with materials in design and science. Through the residencies, the authors gained an increased understanding of how scientific and design materials research proceeds.

\section{DISCUSSION}

The Material Affinity diagram outlines how textile design and materials science can develop new approaches for practical enquiry with materials for a circular bioeconomy. The collaboration has lead to valid material experiments for the designer and visual approaches for the scientist for practical work with materials. While the textile design researcher in this collaboration has a keen interest in working with scientific processes of materials and the technical scientist is interested in exploring design processes, more work needs to be done to explore how both disciplines can effectively collaborate through the practice of materials to achieve a circular economy. It requires openness towards the development of new skills. Collaboration does not involve eliminating working in separate fields, as professional expertise in practical work in science as well as design are needed to achieve a circular economy. Time efficiency, distances between locations and funding are other barriers for collaboration. The luxury of exploration is to be balanced with results, however the freedom of un-linear approaches to collaboration can bring beneficial outcomes.

The first residency highlighted how communication between textile design and material science needs to be improved to support cross-disciplinary collaboration. The collaboration in both residencies evidenced that in order to bring textile design and material science closer together in the scientific processes and production stages of materials in the circular economy, a process of translation needs to take place. As Cross argues that designer need to communicate their practice to scientists (2001), the second design residency in the science laboratory provided a useful case study for the design researcher to prototype and demonstrate the design process to the scientist.

\section{CONCLUSION}

The first and the second residency answered the question from the brief to explore how design and science can inform each other when working with regeneration of cellulose for a circular bioeconomy.

In the first residency, we have outlined the aims and scale of practical work with materials in textile design and materials science. We have highlighted that approaches in both disciplines can be described as production or communication, however that they differ in their methods. Transdisciplinary approaches were found between scientific method and design vision that expand the approaches of production and communication in both disciplines: visualization and validation.

During the second residency the design researcher proceeded with material experiments in a process of validation. The technical scientist adopted visualization as a method for the collaboration and as tools to communicate scientific research to the wider public. The practical work with materials during the residency facilitated a convergence of scientific method and design vision through validation and visualization in a process of "translation'. Improved communication and insights into the processes of materials science and textile design were achieved through the material experiments in the science laboratory.

The collaborative, practical work with materials improved the author's insights into each other's practice. However, it has to be noted that such type of collaboration is an exception: both design practice and scientific research with materials take time. The residencies were initiated by the design researcher in collaboration with the technical scientist: as the research was not application or product-led, but material-driven, residencies in this format require funding and institutional support to exist outside of commercially-driven projects. The residencies form a part of the practice-based $\mathrm{PhD}$ research of the design researcher and were made possible thanks to the collaboration with the technical scientist. The transdisciplinary methods developed by the authors have since the residency continued to inform the practical work of the authors.

This paper addresses "translation" as a process taking place during textile design residencies in the material science laboratory. The material experiments improved cross-disciplinary communication at the convergence of scientific method, design vision, visualization and validation processes. It is to be noted that the design researcher performed the material experiments using the scientific method in the science laboratory in collaboration with the scientist. The authors 
note that the process could also be inversed with a scientist in residence in the design studio to observe, participate and prototype design samples.

\section{ACKNOWLEDGEMENTS}

This $\mathrm{PhD}$ research is funded by the London Doctoral Design Centre (LDoc) of the UK Arts and Humanities Research Council. The residency was supported by the Centre for Circular Design (CCD) at the University of the Arts London, where Miriam Ribul is based, by RISE Research Institutes of Sweden, where Dr Hanna de la Motte is based, and a cohort of scientists: Dr Emma Östmark (RISE), Dr Sara Olsson (RISE), Dr Helena Wedin (RISE) and Dr Carina Olsson (Swerea IVF).

\section{REFERENCES}

Antonelli, P. 2015. Knotty Objects Summit at the MIT Media Lab. Available online at: https:/www.media.mit.edu/video/view/knotty-objects-2015-07-16-01 (accessed January 31, 2016).

Brown, H., Cook, R. and Gabel, M. n.d. Environmental Design Science Primer. Available online at: https://bfi.org/sites/default/files/attachments/pages/EnvDesignPrimer-BrownCookGabel.pdf (accessed June 9, 2016).

Chisholm, H., (ed.) 1911. “Affinity, Chemical." In Encyclopcedia Britannica. $11^{\text {th }}$ edn. Cambridge: Cambridge University Press. Available online at: https://en.wikisource.org/wiki/1911_Encyclop\%C3\%A6dia_Britannica/Affinity,_Chemical (accessed July 6, 2016).

Cross, N. 2001. "Designerly Ways of Knowing: Design Discipline Versus Design Science,” Design Issues, 17(3): 49-55.

Design Council. 2005. The Double Diamond Design Process Model. Available online at: http://www.designcouncil.org.uk/sites/default/files/asset/document/ElevenLessons_Design_Council\%20(2).pdf (accessed July 19, 2016).

Drazin, A. and Küchler, S. (ed.) 2015. The Social Life of Material: Studies in Materials and Society. London: Bloomsbury Publishing.

Drucker, J. 2011. "Humanities approaches to graphical display," DHQ: Digital Humanities Quarterly 5(1). Available online at: http://www.digitalhumanities.org/dhq/vol/5/1/000091/000091.html (accessed February 22, 2018).

Ellen Macarthur Foundation. 2014. Towards the Circular Economy Vol 3. Available online at: http://www.ellenmacarthurfoundation.org/assets/downloads/publications/Towards-the-circular-economyvolume-3.pdf (accessed November 10, 2015).

Hameed, N. and Guo Q. 2010. "Blend films of natural wool and cellulose prepared from an ionic liquid," Cellulose, 17: $803-813$.

Igoe, E. 2010. "The tacit-turn: textile design in design research," Duck Journal for Research in Textiles and Textile Design, 1, 1-11. Available online at: http://www.lboro.ac.uk/microsites/sota/duck/1.\%20The\%20TacitTurn\%20-\%20Elaine\%20Igoe.pdf (accessed October 24, 2017).

Ingold, T. 2013. Making: anthropology, archaeology, art and architecture. Abingdon, England: Routledge.

Ito, J. 2016. "Design and Science." Journal of Design and Science. Available online at: http://jods.mitpress.mit.edu/pub/designandscience (accessed June 9, 2016).

Ito, J. 2014. Antidisciplinary. Available online at: http://joi.ito.com/weblog/2014/10/02/antidisciplinar.html (accessed June 9, 2016).

Karana, E., Barati, B., Rognoli, V., and Zeeuw van der Laan, A. 2015. "Material driven design (MDD): A method to design for material experiences," International Journal of Design, 9(2): 35-54.

Karana, E., Pedgley, O. and Rognoli, V. 2014. Materials experience: fundamentals of materials and design. Oxford: Elsevier.

Küchler, S. 2015. "Materials. The story of use.” In A. Drazin and S. Küchler, (ed.) The Social Life of Materials and Society. London: Bloomsbury Publishing.

Lawrence, R. and Deprés, C. 2004. "Futures of Transdisciplinarity," Futures: the journal of policy, planning and futures studies, 26(4): 397-405. Available online at: http://www.sciencedirect.com/science/article/pii/S0016328703001885.

Lee, S. n.d. Biocouture. Available online at: http:/www.launch.org/sites/default/files/systems2013_innovator_presentations/Biocouture.pdf (accessed June 6, 2016)

Ma, Y., Hummel, M., Määttänen, M. and Sixta, H. 2015. "Upcycling of Waste Paper and Cardboard to Textiles,” Green Chemistry, 18(3): 858-866. Available online at: https://www.researchgate.net/publication/283181773_Upcycling_of_waste_paper_and_cardboard_to_textiles (accessed July 18, 2016).

McNiff, J. and Whitehead, J. 2010. You and your action research project. 3rd ed. London: Routledge. Available online at: http://ebookcentral.proquest.com/lib/ual/detail.action?docID=446724 (accessed February 22, 2018).

Muratovski, G. 2016. Research for designers: a guide to methods and practice. London: Sage Publications Ltd. 
Nijkamp, E. J. S. 2012. Changing the perception of bioplastics. Available online at: http://repository.tudelft.nl/islandora/object/uuid:c49e021e-4986-4e6f-8eeb-991b7ea10eac?collection=education (accessed July 15, 2016).

Östlund, Å., Wedin, H., Bolin, L., Berlin, J., Jönsson, C., Posner, S., Smuk, L., Eriksson, M. and Sandin, G. 2015. Textilåtervinning: Tekniska möjliheter och utmaningar. Available online at: https:/www.naturvardsverket.se/Documents/publikationer6400/978-91-620-6685-7.pdf?pid=15536 (accessed July 5, 2016).

Oxman, N. 2016. "Age of Entanglement," Journal of Design and Science. Available online at: http://www.pubpub.org/pub/AgeOfEntanglement (accessed June 9, 2016).

Peralta C., and Moultrie J. 2010. "Collaboration Between Designers and Scientists in the Context of Scientific Research: A Literature Review," (From the Proceedings of the International Design Conference - Design 2010, Dubrovnik, Croatia, 17-20 May 2010). Available online at: https://www.designsociety.org/downloadpublication/29510/collaboration_between_designers_and_scientists_in_the_context_of_scientific_research_a_lit erature_review (accessed April 15, 2016).

Ribul, M. 2013. Recipes for Material Activism. Available online at: https://issuu.com/miriamribul/docs/miriam_ribul_recipes_for_material_a (accessed November 7, 2016).

Ribul, M. \& and de la Motte, H. 2016. "The Material Affinity of Design and Science for a Circular Economy," Proceedings of the Circular Transitions Conference, London, United Kingdom, November 23-24, $236-248$. Available online at: http://circulartransitions.org/media/downloads/Circular-Transitions-Proceedings.pdf (accessed January 15, 2018).

Reason, P. and Bradbury, H. (ed.) 2006. Handbook of action research. London: Sage.

Rittel, H. and Webber, M. 1973. "Dilemmas in General Theory Planning," Policy Sciences, 4(2): 155-169. Available online at: http://web.a.ebscohost.com.arts.idm.oclc.org/ehost/pdfviewer/pdfviewer?sid=570b10da-cd76-4fa88634-807337ec254f\%40sessionmgr4004\&vid=1\&hid=4206.

Rust, C. 2004. “Design Inquiry: Tacit Knowledge and Invention in Science,” Design Issues, 20(4): 76-85.

Sawyer, R. K. 2006. Explaining creativity: the science of human innovation. Oxford: Oxford University Press.

Science Community Representing Education, SCOR. 2008. Practical Work in Science: A Report and Proposal for a Strategic Framework. Available online at: http://www.score-education.org/media/3668/report.pdf (accessed July $5,2016)$.

'Scientific Method'. n.d. Wikipedia. Available online at: https://en.wikipedia.org/wiki/Scientific_method (accessed July 6, 2016).

Sundberg, J., Toriz, G. and Gatenholm, P. 2013. "Moisture induced plasticity of amorphous cellulose films from ionic Liquid," Polymer, 54: 6555-6560.

Van Bezooyen, A. 2014. 'Materials Driven Design.' In E. Karana, O. Pedgley and V. Rognoli (eds.) Materials experience: fundamentals of materials and design. 277-286. Amsterdam; London: Butterworth-Heinemann.

Vezzoli, C. 2014. "The 'Material' Side of Design for Sustainability." In E. Karana, O. Pedgley and V. Rognoli (eds.) Materials experience: fundamentals of materials and design. 105-121. Oxford: Elsevier.

Wilkes, S., Wongsriruksa, S., Howes, P., Gamester, R., Witchel, H., Conreen, M., Laughlin, Z. and Miodownik, M. 2015. "Design tools for interdisciplinary translation of material experiences," Journal of Materials \& Design. doi: $\quad 10.1016 /$ j.matdes.2015.04.013. Available $\quad$ online at: http://elearning.instituteofmaking.org.uk/uploads/wilkes-et-al-2015.pdf (accessed October 13, 2016). 